\title{
A Critical Appraisal of Theory and Methodology of Irrigation Systems in the Chemical Debridement of the Root Canal System
}

\author{
${ }^{1}$ My Dentist, Stone Dental Practice, UK \\ ${ }^{2}$ My Dentist, Europa House, UK \\ ${ }^{3}$ Bupa Dental Care, UK \\ ${ }^{4}$ Great Dunmow Dental Care, UK \\ ${ }^{5}$ Foxland Dental Surgery, UK
}

Al Yamoor R ${ }^{1}$, Stefanescu SV ${ }^{2 *}$, Buciu A ${ }^{3}$, Senchea CE $^{4}$ and Haider Al-Saffar ${ }^{5}$

\section{Review Article \\ Volume 6 Issue 1}

Received Date: February 04, 2021

Published Date: February 19, 2021

DOI: $10.23880 /$ oajds-16000287

*Corresponding author: Stefan V Stefanescu, Europa Trading Estate, Stoneclough Road, Manchester M26 1GG, United Kingdom, Tel: +44-7712702307; Email: amedeo_1@yahoo.com

\section{Abstract}

Irrigation of the endodontic space is one of the most important steps in the chemical-mechanical treatment of the root canal. Since endodontic infections have been shown to be a result of the microbial factor, debris, bacterial biofilm, planktonic bacteria and pulp tissue removal by means of irrigation has gained significant emphasis over the past half century. No sector of endodontics has undergone so much change and raised so much interest, resulting in thousands of studies, as the irrigation of the endodontic space. Studies do not continue to flow, theories do not cease to be formulated, hypotheses do not cease to be launched, new and new techniques and devices are launched on the market in order to optimize this process both in time and effect. The present study aimed to review the most popular methods, not all, along with the most used irrigants, not all of them.

Keywords: Irrigation; Endodontic; Root; Tooth; Dental

Abbreviations: PUI: Passive Ultrasonic Irrigation; SUI: Simultaneous Ultrasonic Irrigation; RE: RinsEndo.

\section{Introduction}

Root canal treatment is a chemo-mechanical process that removes a smear layer (a morpho irregular infected bacterial layer consisting of organic, inorganic tissue, and debris like saliva, blood, and dentinal chips) from infected root canal walls [1]. Therefore, root canal irrigation is considered as a vital part of canal treatment success [2]. There are variable irrigation systems used in Endodontology; their effectiveness can depend on the depth of liquid penetration and tissue dissolving ability [1]. Nevertheless, Gentle Wave Systems GWS (Sonendo, Inc., Laguna Hills, CA, USA), Sonic EndoActivator (Dentsply Tulsa Dental Specialties, Tulsa, OK, USA), pressure alternative devices EndoVac (EndoVac;
Discus Dental, Culver City, CA) are considered as an active negative pressure system. Meanwhile, root canal needle, XP-Endo Finisher files (FKG Dentaire SA, La Chaux-deFonds, Switzerland), and Endodontic brushes (C\&S Micro instruments Ltd, Markham, Ontario, Canada) act as a passive pressure irrigation system [3].

The mechanism of action of the negative pressure irrigation system could depend on developing acoustic streaming and cavitation (hydrodynamic pressure), rapid circular movement of irrigants around the vibrating tip. Meanwhile, the cavitation is by creating vapor bubbles and disfiguring the existing bubble within the irrigation solution to achieve irrigants agitation that would be more effective in removing debris in the apical area than the positive pressure needle method [4]. Furthermore, there is an obvious risk of apical extrusion of irrigation solutions that may lead to apical 
tissue inflammation like swelling, pain, and tissue damage. Nevertheless, this risk with a sonic driven device is less than passive ultrasonic continuous irrigation flow and sidevented needle [5,6]. EndoVac and EndoActivator pressure devices have less extrusion ability than the RinsEndo irrigation systems (RinsEndo, Co. Duerr- Dental, BittigheimBissingen, Germany). Furthermore, a high-frequency ultrasonic system had proven to be more effective in debris removal, particularly around the root canals grooves, than other methods $[7,8]$. In addition to that, the Diode Laser has shown to have a potent bactericidal effect by enhancing the activation of the irrigation solutions [9]. Nevertheless, the Gentle Wave system with irrigants showed potent soft tissue dissolving ability [10].

\section{The Gold Standard Irrigation Solutions}

\section{Sodium Hypochlorite NAOCL 0.5\%-6\%}

The most commonly used Endodontic irrigation solution has an antibacterial effect and the smear layer's organic tissue dissolving ability [11]. Hypochlorite was used for the first time in France in 1789 as a hospital antiseptic under Eusol and Dakin's solution as wound antiseptic. Later on, in 1936, NAOCL was used for dental treatments $[5,12]$.

NAOCL can lead to potent components like formaldehyde, acetaldehyde, and chloramines after contact with bacterial cell walls like nitrogen and protein. Furthermore, leading to protein and peptide links breakage resulting in hydrogen replacement with the amino group (chlorine) [13]. Chlorine inhibits bacterial enzyme irreversibly. Furthermore, NAOCL exhibits a Saponification reaction, a fat and organic solvent reaction that degrades fatty acid, leading to fatty acid salt (soap) and glycerol (alcohol). Therefore, it can form hypochlorous acid (HOCL-) that acts as an oxidizer agent due to the chlorine dissolves in water in conjunction with hypochlorite ions (OCL-) will lead to amino acid hydrolysis and degradation. On the other hand, NAOCL has a high $\mathrm{pH}$ of more than 11, which can interfere with bacterial cytoplasmic membrane integrity due to the irreversible enzymes' inhibitor [13].

NAOCL has a few side effects like toxicity and irritation. However, the antibacterial effect is directly related to increasing concentration. It has an oxidative effect on bacterial enzymes like hypochlorous acid on the sulfhydryl groups that interfere with bacteria metabolism [14-16].

\section{Ethylenediamine Tetra-Acetic Acid (EDTA 17\%)}

EDTA is a polycarboxylic amino acid that is colourless and water-soluble [17]. EDTA is a chelating agent used to remove the smear layer's inorganic component by removing the hard tissue (decalcification). EDTA segregates di-tricationic metal ions such as $\mathrm{Ca} 2+$ and $\mathrm{Fe} 3+$ and extracts protein after binding to the bacterial cell envelope $[11,17]$. Nevertheless, EDTA can leave the organic fibrous tissue in the root canal and acts as an antibacterial solution; on the other hand, EDTA is very active in creating the root dentinal tubules patency [1]. However, it has a little bactericidal effect [14].

\section{Irrigant's Techniques and Devices}

\section{Manual Passive Irrigation Methods}

Syringe irrigation with needles/cannulas like endventing; side-venting: This method can be considered as an acceptable form of irrigation used by Endodontists and general practitioners, using the side-vented (KerrHawe Irrigation Probe; KerrHawe SA, Bioggio, Switzerland) or open-ended needles (NaviTip; Ultradent, South Jordan, UT) with the use of the cannula passively or by agitation. The liquid activation can move the needle up and down to develop a hydrodynamic activation of the irrigants with a high risk of apical extrusion. The needle should remain loose within the root canals to enhance more debris reflux coronally; hence 27gauge needle is the most preferred in endodontology. The irrigant can deliver through the needle tip or by its side [11]. There is clear evidence that using an irrigation syringe can control the needle depth within the root canal; however, it can produce flawed mechanical flushing with a limited depth of penetration in the narrow roots that can lead to incomplete root debridement. Therefore, the root canal enlargement would be considered for better flushing action of debris; nevertheless, there is a high risk of reducing the radicular dentine thickness [5,6,11].

Rotary brushes (NaviTip Brushes) \& Endodontic brushes: Endodontic brushes (C\&S Micro instruments Ltd, Markham, Ontario, Canada) are well-founded as an active rotary system made of nylon bristles that fit on a twisted wire with a handle [11]. The Endobrush can fit inside the root canal wall within 2-3 mm from its full working length (to avoid packing the debris into the apical third of the root) with 90-degree rotary motion combined with a pull-push movement for 1 minute [11]. The NaviTip brushes (NaviTip FX; Ultradent Products Inc, South Jordan, UT) are a bristle brushes cover the 30-gauge irrigation needle. The mechanism of action is accomplished by scrubbing the brush into the root canal wall to improve irrigation efficacy. Nevertheless, the friction can lead to dislodgement of radiolucent bristles that the clinicians cannot detect macroscopically or by the microscope [11]. Manual-dynamic agitation: Hand-activated gutta-percha: This method based on using the master cone gutta-percha that fits inside the instrumented root canal 2-3 mm within push-pull strokes, which lead to the development of the hydrodynamic effects that improve the debris displacement; 


\section{Open Access Journal of Dental Sciences}

this method is associated with a high risk of liquid extrusion [11].

XP files: XP-Endo finisher files (FKG Dentaire SA, La Chauxde-Fonds, Switzerland) are a new Nickel-Titanium rotary finisher that claims to have high flexibility as it forms from different temperature. XP Files can operate at 800rpm for 60 seconds after canal instrumentation with irrigants to properly clean, especially with the curved root canals. This technique requires good care as it can associate with a file separation within the canal $[2,11]$.

\section{Machine Assisted Methods}

Ruddle and Canal Brushes: Ruddle brushes are attached to a rotary handpiece to remove the smear layer from instrumented root canals [11]. The brush consists of a tapered end that has multiple bristles which are extended from the wire core. The canal micro-brushes are made of polypropylene, designed to fit the contra-angle handpiece at 600rpm speed [11]. Meanwhile, endodontic brushes are more flexible micro brushes that can run manually with a rotation action but more effective when operating with a contra-angle handpiece at $600 \mathrm{rpm}$. Furthermore, the bristles could deform into an irregular canal, which helps displace the debris coronally and enhance the irrigant action [11].

Continuous Irrigation during Rotary Instrumentation Quantec-E System: This pump system can consider as a fluid delivery unit attached to Quantec-E Endo system (SybronEndo, Orange, CA), which is made of 2 irrigation reservoir, a pump console, and tubing to provide continuous irrigation during root canal instrumentation. Furthermore, this method could increase irrigant volume, exposure time, depth of penetration within the root canals, the effective smear layer elimination compared with manual processes [11].

Sonic irrigation system: The sonic irrigation system was used for the first time in 1985 [18]. The Sonic irrigation has the advantage of producing more effective root canal debridement $[15,19]$. Sonic devices are different from ultrasonic devices. They work with lower frequency (1$6 \mathrm{Khz}$ ), small shear stress, and higher amplitude (more significant back and forth movement) with longitudinal oscillation movement EndoActivator is one of the sonic systems varieties [20].

EndoActivator sonicirrigation system: The EndoActivator sonic irrigation system (Dentsply Tulsa Dental Specialties, Tulsa, OK, USA) consists of a handpiece, three disposable polymer tips of variable sizes (Yellow15/02, Red25/04, Blue35/04), and a battery that activates the sonic handpiece from 2000-10000 cycles/min [7].

There were no differences in EndoActivator sonic tips' cleaning efficiency when using a variable frequency [4]. The
EndoActivator system can provide better cleaning results when operating at $0.166-0.3 \mathrm{kHz}$; nevertheless, the same study investigated the Eddy system's use of a different sonic system. This system can run at $6000 \mathrm{hz}$ by an air-driven handpiece that can produce a high vibration frequency and oscillating tip movement. This process will help acoustic streaming and cavitation, enhancing the cleaning efficiency, leading to more debris removal than other systems [15].

Ultrasonic irrigation system: The ultrasonic driving device has a direct cleaning efficiency due to the frequency and oscillating amplitude of its vibrating tip inside the root canals; therefore, increasing the tip's frequency and oscillation will increase the flow velocity of solutions inside the canals. Hence, there is more smear layer removal than sonic activation [21].

Ultrasonic irrigation systems were introduced in endodontology for the first time by Richman. There are two types of ultrasonic irrigation systems like simultaneous ultrasonic irrigation (SUI), a file that contacted root canal during instrumentation that reduces the oscillation and acoustic streaming function with more dentine cutting ability and this can lead to perforation of the canals and irregular canal shaping. Nevertheless, the passive ultrasonic irrigation system (PUI), which is a small file that can move freely within the canal without cutting action (canal size file 30), this will enhance the acoustic streaming [11]. Passive ultrasonic needle (PUI) irrigation system continuously delivers irrigation liquids, better cavitation, acoustic streaming to the root canals, and pulp tissue removal than hand or rotary file systems [11].

Nusstein has created a needle-holding adapter to the ultrasonic handpiece. A size 25-gauge needle was used during ultrasonic activation to obtain maximum power with a low risk of needle breakage. Furthermore, the irrigant deliver to the instrumented canal from an intravenous tube that attached by using Luer-Lok to irrigation syringe and allow the liquid to provide continuity to the apical third of the canal with the high cleaning capacity.

One study illustrated that using PUI with 3\% NAOCL showed complete elimination of the smear layer compared to using PUI with water $[7,11,22]$.

\section{Pressure Alternating Devices}

\section{EndoVac system}

John Schoeffel discovered the EndoVac system (EndoVac; Discus Dental, Culver City, CA) as a negative pressure irrigating system [23]. EndoVac can draw the irrigant apically by using a high-volume evacuation suction of the dental unit, which can help deliver the irrigants to more challenging 


\section{Open Access Journal of Dental Sciences}

irregular canal anatomies like isthmus oval-shaped canals [23]. Furthermore, EndoVac was used to overcome the apical vapour lock (an air that entrapped at the root canal) [24].

The EndoVac system consists of 3 components: The Macro plastic, Micro stainless-steel negative pressure cannulas, and master delivery tip (MDT), which simultaneously evacuate and deliver the irrigation solution. The Macro cannula is used to produce the irrigants to coronal and middle thirds of the roots. Simultaneously, the EndoVac Microcannula; (Discus Dental, Culver City, CA) has 12 holes $0.2-0.7 \mathrm{~mm}$ from the tip end users to deliver and evacuate the irrigation liquids to the full working length $[7,21]$. The MDT first delivers the NAOCL against the pulp chamber walls and uses it after each canal instrumentation. After completion of instrumentation, the macro cannula was used for up and down motion as close as working length to eliminate the smear layer following a micro-cannula to a full working length $[7,21]$.

\section{RinsEndo (RE)}

RinsEndo irrigation system (RinsEndo, Co. Duerr- Dental, Bittigheim-Bissingen, Germany). The alternating pressure devices that function based on a hydrodynamic activation (a pulsing movement of the irrigation solutions) and pressuresuction technology to flush the canals can be considered the canals (Inside Dentistry 2007) [25] thoroughly.

The RE had demonstrated the effectiveness of cleaning the curved, complicated canals and delivering the irrigant apically without risk of extrusion compared to other irrigation techniques with adequate time. The volume aspirated through the handpiece is 40 seconds, the flow rate metered $6.2 \mathrm{ml}$ per minute, and it can heat NAOCL (Inside Dentistry 2007) [25].

The pressure-suction system consists of a titanium handpiece, which is the autoclave, a disposable $7 \mathrm{~mm}$ elongate exit aperture cannula that is ultra-thin and flexible (which are locked to the handpiece by twisting motion) that facilitate easy movement of liquids without canal blockage, a disposable irrigation syringe and dental air compressor that operates the handpiece at $6.2 \mathrm{ml} / \mathrm{min}$ [7].

The operation is based on a pressure phase that involved $65 \mathrm{ml}$ of irrigant withdraw from the syringe and aspirated inside the canal, then suction phase through which the irrigant can be removed from the canals. The RE delivers air pressure to a maximum of five psi to avoid the risk of pressure-induced apical perforation or extrusion; the pressure-suction cycles can exchange 100 times per minute (Inside Dentistry 2007) [25].

\section{Other Methods of Active Irrigation}

The Laser: The Laser was introduced in dentistry in 1971. The clinical use became common in the late 90s for several treatments like pulp capping, cleaning and disinfection of the root canals, obturation, re-treatment, and apical surgery. Different types of laser wavelengths are used in endodontic cleaning and disinfecting roots like carbon dioxide (CO2), 9600 and $10600 \mathrm{~nm}$ wavelength, erbium: yttrium aluminum garnet (Er: YAG), $2940 \mathrm{~nm}$; erbium, neodimium: yttrium aluminum garnet (Nd: YAG), $1064 \mathrm{~nm}$; diode, 635 to $980 \mathrm{~nm}$, erbium, and chromium: yttrium scandium gallium garnet (Er, Cr: YSGG), $2780 \mathrm{~nm}$ [15]. The phenomena of tissue and bacterial cells absorption of the exposed laser wavelengths are called a photothermal reaction. The photothermal response will increase the cell temperature and lead to bacterial DNA and cell membrane damage [26,27]. There are several limitations of using the Laser in endodontic treatment: unequal radiation exposure to all root canal thirds, a high chance to develop ledges and perforation in the curved canal, and thermal damage apical tissue with open foramen [9].

Diode Laser (DL): The laser effects had shown great promise in root treatment and antibacterial effect in conjunction with using the NAOCL solution. Diode laser showed greater penetration depth within $1 \mathrm{~mm}$ of dentinal tubules. The Diode laser emits radiation within a visible wavelength $(660 \mathrm{~nm})$ and infrared range of the electromagnetic spectrum (810980). Diod Laser has a high-water absorption coefficient capacity $(0.68 \mathrm{~cm}-1)$, leading to low penetration depth inside dentin $(750 \mathrm{Mm})$ in comparison to $\mathrm{Nd}$ : YAG laser type. Therefore, the Diode laser had limited usage in root canal treatment. Nevertheless, a recent study has delineated that the Diode laser has a significant role in disinfectant with the NAOCL [14].

Antimicrobial photodynamic therapy (APDT): The APDT or photoactivated disinfection (PDA) is a laser enhanced photochemical sterilization using a low energy laser wavelength to activate photosensitizers (PS), a nontoxic photoactive chemical dye. When exposed to different wavelengths, light and oxygen can produce a reactive oxygen species (ROS), leading to bacterial cytotoxic damage to the cellular plasma membrane or DNA [15]. Furthermore, APDT benefits from being non-toxic, short lifetime, costly reasonable, the interval between administration and peak accumulation within the tissue should be short with high cytotoxic productivity. However, The APDT success rate relies on the dose, incubation time, type of APDT, photosensitizers and oxygen presence, light wavelength $(\mathrm{nm})$ sources like diode laser at $670 \mathrm{~nm}, 630 \mathrm{~nm}$, and $660 \mathrm{~nm}$ Helium: Neon Laser and dye like methylene blue, tolonium chloride, power density, and energy fluency [28]. 


\section{Open Access Journal of Dental Sciences}

C-Er: YAG and Er, Cr: YSGG laser, Er: YAG $2940 \mathrm{~nm}$ and Er, Cr: YSGG $2790 \mathrm{~nm}$ is mostly used due to their high water and root wall crystal absorption at $300-400 \mathrm{~mm}$ with smear layer elimination and superficial antibacterial effect $[9,29]$.

Erbium Lasers are used for laser-activated irrigation (LAI) by creating cavitation and acoustic stream phenomena of the canal fluids. Intracanal water and NAOCL absorb Erbium laser at a low energy setting of $50-75 \mathrm{~mJ}$, which would enhance irrigants' evaporation and elliptical vapor bubbles. On the other hand, there is a high chance of volumic expansion of irrigants up to 1600 times more than the original volume, elevate intracanal pressure, and ultimately drive fluids into the canal [9].

\section{Gentle Wave System (GWS)}

The GWS (Sonendo, Inc., Laguna Hills, CA, USA) is an active irrigation method that uses acoustic energy and degassed irrigants to eradicate debris and assist in soft tissue dissolving ability high safety rate from apical extrusion of irrigants by the effect of negative pressure function. Furthermore, there was a more than $95 \%$ success rate of root canal treated with GWS after yearly follow up [30,31].

The GWS function includes: Hydrodynamic cavitation, which creates vapor bubbles, then disfiguring the existing bubble within the irrigation solution, then a broad spectrum of sound waves that travel through the degassed treatment fluid propagates throughout the entire root canal system. GWS will enable irrigation solutions to reach problematic areas of the root canal walls. The GWS should be avoided in the immature open apex of root canals to prevent apical extrusion of irrigants [32]. GWS has two components: a console and a disposable handpiece, which sit on the tooth pulp chamber to access the root orifices, as illustrated in figure 3. Also, GWS showed better cleaning ability than conventional needle irrigation and ultrasonically irrigated teeth [33].

\section{Comparison between Active and Passive Irrigation Methods in}

\section{Smear layer removal}

Guo, et al. [34] demonstrated the effectiveness of smear layer removal from coronal, middle, and apical root canal thirds by using an elevated temperature of 3\% NAOCL and $17 \%$ EDTA with four different irrigation systems like sided vented needle syringe, an ultrasonic device like a piezoelectric unit, 30- gauge Navi Tip FX needle, and EndoActivator tips device. Fifty single root teeth that divided into five groups irrigated by four different irrigation techniques: the tips of devices inserted deeply and moved freely inside the canals without canal binding. Moreover, they used not agitation irrigation system like a sided-vented needle inserted at the canals' orifices.

After full canal instrumentation, the canals had final irrigation with $1 \mathrm{ml}$ of $3 \%$ sodium hypochlorite for 1 minute at 60 degrees Celsius at $1 \mathrm{~mm}$ of the root working length shorter than the original length. The next step in the management includes irrigation by $5 \mathrm{ml}$ sterile distilled water; furthermore, irrigation with $1 \mathrm{ml}$ of $17 \%$ EDTA for 1 minute with the irrigation systems freely within the canals, and finally, the canals were dried with a paper point. The remaining a smear layer amounts in the coronal, middle, and apical thirds of the root canals were evaluated and showed that the smear layer elimination from the different thirds of the root canal was considered as incomplete by all irrigation methods, particularly in the apical third compared to the middle and coronal thirds. Nevertheless, this study concluded that the ultrasonic irrigation method showed a less effective method of removing the smear layer than other methods like NaviTip FX or EndoActivator due to the device tip binding the root canal wall during irrigation, which in turn can create dentinal chips and more smear layer. Furthermore, the efficacy of NAOCL will increase by elevating its temperature and using active irrigation methods. However, the study showed no difference in effective smear layer removal using activation or non-activation techniques in all different root canal thirds.

Charara, et al. [35] demonstrated the variable physical and chemical activation of the alkaline components of $5 \%$ NAOCL and 17\% EDTA during root canal irrigation with less risk of fluid extrusion. Furthermore, they used different irrigation techniques to physically agitate the canals like mechanical vibration, ultrasonic devices, and the infrared Laser.

They also used a chemical irrigation liquid to dissolve the canals' wall hard and soft tissue to improve irrigants' flow, particularly within the small canals. The debris removal from the canals was used to assess the cleaning ability, which was scored using the scanning electron microscopy (SEM), digital image analysis, confocal microscopy, and micro-computed tomography. The smear layer resorption increased by using Laser and ultrasonic energy, which will create a fluid motion to an area that cannot be accessed with hand or rotary files. Elnaghy, et al. [2] demonstrated the XP-Endo-Finisher file's role, EndoActivator, in debris removal from mandibular curved roots.

Seventy-five extracted infected curved mandibular teeth were divided into five groups. Fifteen teeth were enrolled in each group. The teeth were instrumented using BT-RACE rotary system and exposed to different irrigation liquids 


\section{Open Access Journal of Dental Sciences}

of $2.5 \%$ NAOCL and 17\% EDTA using a 30-gauge needle syringe. Group l was the lively group with no final rinse or file agitation, while group 2 has $5 \mathrm{ml}$ final rinse with 17\%EDTA without liquid agitation. Group 3 used the final rinse with $5 \mathrm{ml}$ of $17 \%$ EDTA and BT2 file agitation for 60 seconds. Meanwhile, in group 4, XP-endodontic finisher files were inserted to the full working length of root and agitated with $17 \%$ EDTA set at $800 \mathrm{rpm}$ for 60 seconds and finally, group 5 used the red tip EndoActivator sonic device (ISO 25/0.04) that extended to full working length to agitate the 17\% EDTA at ten 000 cycles/min for one minute. The study used the scanning electron microscopy to analyse the debris score from longitudinally split root canals in the coronal, middle, and apical areas.

The XP-files and EndoActivator showed the best methods and less debris detection apically than other study groups. Nevertheless, there was a high debris score in the lively nonrinse group in all root canal parts. Also, irrigants' agitation can enhance the liquid's temperature, penetration, and debris removal from the infected curved root canals.

The study by Widjiastuti, et al. [3] illustrated the differences in using positive and negative pressure irrigation methods in the more complex root canal area's cleaning efficiency. They recruited 27 mandibular single root premolars that were instrumented into a variable working length of $18-20 \mathrm{~mm}$. The root canals were cleaned between instrumentation stages by using $2.5 \%$ NAOCL then distilled water. Based on the different irrigation systems that applied, they were divided into three groups. The positive sidevented needle control group (c), the positive port -vented needle irrigation system (T1), and the Negative irrigation system Vpro Endo Sav device (Vista Dental, South St, Racine, USA) (T2). Kruskal Wallis, Mann Whitney, and Spearman correlation tests were used to analyse the results of liquid replacement and removal of debris from apical root canals. They concluded that the negative pressure irrigation system produced superior apical penetration and debris removal compared to the positive pressure irrigation system.

\section{Bactericidal Effects against Enterococcus Faecalis of the Infected Root Canals}

Dai, et al. [36] showed an aseptic effect of a Diode laser(810nm) against Enterococcus Faecalis in primary human teeth. They selected 80 infected mandibular primary teeth with Enterococcus Faecalis, divided them into four groups, irrigated differently after instrumentation. Group one was the positive group, which was irrigated with $2.5 \%$ NAOCL. In comparison, the second group was a non-irrigated negative group. The third group was exposed to a Diode Laser, and the fourth group was a mixture of Diode Laser and

\section{NAOCL treatment.}

The account of bacteria was analysed and counted by using scanning electron microscopy SEM (which is a versatile tool that can define the feature of the sample from $100 \mathrm{pm}$ 100micrometer) and (live-dead staining) Laser microscopy [37]. The study results showed that using a combined Laser exposure with NAOCL produced a $100 \%$ bactericidal effect than any other group.

Furthermore, Jurič \& Anić [15] demonstrated the antibacterial role of photodynamic therapy in removing Enterococcus Faecalis from infected milk and adult root canals. The study recruited 160 infected extracted single root teeth, which were divided into three groups. Group one included 70 adult front and premolars re-infected teeth shaped by using a pro taper system to clean the canal then the canal was filled with thermal and $\mathrm{AH}+$ cement. After 24 hours, the filling was removed with a size D pro taper file, three \%NAOCL, and plasma then the roots were occupied by E Faecalis for 72 hours. Group two (control group) had 20 specimens roots free of E Faecalis. Meanwhile, group 3 included 70 specimens of primary infected teeth. The primary infected teeth were divided randomly into four groups.

Furthermore, each group had 20 teeth, except for one group had ten teeth. Group one was exposed to photosensitizer toluidine blue and APDT light source at $635 \mathrm{~nm}$. Group 2 was rinsed with $10 \mathrm{ml} 3 \%$ NAOCL alone; however, group 3 used a combination of PDT- 3\% NAOCL, $10 \mathrm{ml}$ of $3 \%$ NAOCL then the teeth were exposed to PDT. Meanwhile, group 4 included ten teeth rinsed with Ringer's solution (an isotonic solution has several salts resorbed in water can use on experimental tissue or organs). The samples of E Faecalis were collected using sterile paper points.

ANOVA test was used to analyze the bacterial number in each group. The group that used NAOCL has the most bactericidal effect against Enterococcus Faecalis than the PDT group alone and the NAOCL-PDT group.

The study concluded that PDT has a potent antibacterial effect against Enterococcus Faecalis, particularly for primary and retreated adult infected root canals $[15,38,39]$. Xiaogang C, et al. [40] demonstrated the Laser's bactericidal effect compared to different techniques like a photon- initiated photoacoustic streaming and 27-gauge side-venting needle syringe eliminate Enterococcus Faecalis. There was more than $80 \%$ bactericidal effect of the Laser at $10 \mathrm{~Hz}$ for 15 seconds. The bactericidal effect increased by $97 \%$ at setting the energy to $200 \mathrm{~mJ}$ for 20 seconds, and more than $99 \%$ achieved at $1.5 \mathrm{~W}$ for 5 seconds. The irrigation liquids and the laser tip penetration depth inside the root canal are 


\section{Open Access Journal of Dental Sciences}

considered essential factors in bacterial and smear layer elimination. Nevertheless, activated NAOCL by Nd: YAG laser irradiation showed a maximum bactericidal effect [41].

\section{Liquids Apical Extrusion}

Plotino, et al. [18] compared irrigants' safety apical extrusion with various irrigation systems like the Novel Gentle Wave system, Conventional open-end 30 Gauge needle $(\mathrm{CN})$, and the EndoVac system in the root canal with or without apical constriction.

Sixteen mandibular molars teeth were mounted in apparatus and immersed in a distilled water pressure control chamber at $5.88 \pm 0.15 \mathrm{mmHg}$ to assess the backpressure peri-apically. The teeth had a mesiobuccal root curve less than 30 degrees and straight canal teeth distally. Furthermore, the teeth were divided into three groups regarding instrumentation methods, group one minimally instrumented with size 15/04 file shorter than the standard working length of roots, group two root instrumented with full working length with size 35/06 file. In contrast, the roots were over instrumented with size 35/06+1 mm over the average working length in group three. The canals are irrigated with distilled water using irrigation systems like GWS, EV, and CN; then, the canals are tested five times each time. The extrusion water frequency and mean extrusion mass in gram were calculated and compared to each irrigation system and canal groups.

The study concluded that using a negative pressure system like GWS and EV produces better results with no apical extrusion of irrigants than the positive pressure endodontic conventional needle $\mathrm{CN}$.

Desai, et al. [7] illustrated the safety of liquid's apical extrusion from the root canals using different irrigation devices like EndoVac, EndoActivater, RinsEndo(RE) (Air Techniques Inc, New York, NY), Max-I prob port needle (Max-I-Probe; Dentsply International, York, PA), and passive ultrasonic irrigation (PUI). Twenty-two extracted mature incisors teeth were used. The teeth were instrumented and irrigated with NAOCL then placed in a lid $20 \mathrm{ml}$ oscillating vial hole to measure the NAOCL extrusion out of the root canals after using each system. Scheffe' test used to analyse the study results; statistically, a post-hoc-test was used to make unplanned comparisons among groups as an analysis of variance (ANOVA) experiment.

There was no apical extrusion detected from the Macro and Micro EndoVac system. Nevertheless, there was a very minimal amount of liquid extrusion by using the EndoActivator sonic system. However, the manual side- ported needle positive pressure, ultrasonic, and RinsEndo systems reported a more significant apical liquid extrusion than EndoVac and EndoActivator.

This study showed that using the ultrasonic system produces a superior result with a high risk of liquids extrusion. Meanwhile, the sonic system is considered a safe method.

Gupta, et al. [30] demonstrated the different techniques of using irrigation systems and their effect on liquids' apical extrusion from root canals like needle syringe, gutta-percha cones, hand files, canal brushes, Lentulospiral, sonic and ultrasonic irrigation systems. In a closed chamber apparatus, they used thirty dry, clean glass vials with rubber stoppers. All specimens were inserted up to cementoenamel junction under pressure. Cyanoacrylate was used to seal the margins. The vial was full of premeasured volume $(5.5 \mathrm{~mL})$ of distilled water, and the apical $3 \mathrm{~mm}$ of root tip was inserted into it without a direct connection. However, in open chambers, set thirty chambers were prepared as above, and the air pressure was balanced inside and outside by inserting a bent 27-gauge needle down beside the rubber stopper. An electronic syringe pump was used to deliver the irrigant at a constant flow rate of $0.26 \mathrm{~mL} / \mathrm{s} .0 .5 \%-5.25 \%$ NAOCL and $17 \%$ EDTA were used as standard irrigation liquids. The liquid agitation has mechanically improved the irrigant's action in debris removal. There was a weak mechanical flushing action by using conventional endodontic syringe needle and canal brushes. Nevertheless, the liquid activity was improved using fit cone gutta perch with up and down motion within the instrumented root canals.

Lentulosprial that rotated with a slow handpiece was mainly used to seal the root sealer and cement inside the canals. EndoActivator sonic system showed precise efficiency in debris removal from the complicated root canal. Using the EndoVac irrigation system illustrated the potent debris removal without apical extrusion of the liquids. PUA was the passive ultrasonic oscillating instrument that activates the irrigants. This study showed a good result in the smear layer and root debris elimination with sufficient shear force (acoustic streaming) [42-53].

This study showed that negative air pressure has a low apical extrusion of irrigants compared to positive pressure. EndoActivator extruded more debris than canal brushes and Lentulosprial; however, less significant compared to PUA. On the other hand, PUA created acoustic streaming and cavitation in debris removal, while sonic irrigation produces only acoustic streaming. Therefore, the PUA efficiency is considered the best cleaning agitation system than other systems but with more apical extrusion. 


\section{Conclusion}

The clinicians should be aware of the importance of delivering the most potent and safe chemo-mechanical root canal treatment. The active irrigation systems showed a potent action in smear layer removal, facilitate the depth of irrigants' penetration within the complicated root canal morphology like small curved canals. Furthermore, the active system showed a low risk of liquid extrusion. A dynamic irrigation system like ultrasonic and sonic devices, GWS, and the Laser showed a superior cleaning efficiency than traditional manual techniques. However, the manual hydrodynamic methods are a simple, cost-effective method in almost dental practices but less effective in debris elimination with the risk of liquid extrusion. Furthermore, the active systems are expensive, required good maintenance, training, and experience. The ultrasonic system is regarded as the gold dynamic irrigation system in comparison with other systems.

\section{References}

1. Zan R, Kutlu G, Hubbezoglu I, Sumer Z, Tunc T, et al. (2015) Bactericidal effects of various irrigation solutions against staphylococcus aureus in human root canal. J Istanb Univ Fac Dent 49(1): 19-26.

2. Elnaghy AM, Mandorah A, Elsaka SE (2017) Effectiveness of XP-endo Finisher, EndoActivator, and File agitation on debris and smear layer removal in curved root canals: a comparative study. Odontology 105(2): 178-183.

3. Widjiastuti I, Rudyanto D, Yuanita T, Bramantoro T, Aries Widodo W (2018) Cleaning Efficacy of Root Canal Irrigation with Positive and Negative Pressure System. Iran Endod J 13(3): 398-402.

4. Jiang L, Verhaagen B, Versluis M, Sluis L (2010) Evaluation of a Sonic Device Designed to Activate Irrigant in the Root Canal. J Endod 36(1): 143-146.

5. Walsh LJ, George R (2017) Activation of Alkaline Irrigation Fluids in Endodontics. Materials (Basel) 10(10): 1214.

6. Mayer BE, Peters OA, Barbakow F (2002) Effects of rotary instruments and ultrasonic irrigation on debris and smear layer scores: a scanning electron microscopic study. Int Endod J 35(7): 582-589.

7. Desai P, Himel V (2009) Comparative Safety of Various Intracanal Irrigation Systems. Endod J 35(4): 545-549.

8. Alkahtani A, Al Khudhairi TD, Anil S (2014) A comparative study of the debridement efficacy and apical extrusion of dynamic and passive root canal irrigation systems. BMC
Oral Health 14(1): 12.

9. Ozses Ozkaya B, Gulsahi K, Ungor M, Gocmen JS (2017) A Comparison of Er: YAG Laser with PhotonInitiated Photoacoustic Streaming, Nd: YAG Laser, and Conventional Irrigation on the Eradication of Root Dentinal Tubule Infection by Enterococcus Faecalis Biofilms: A Scanning Electron Microscopy Study. Scanning 2017: 6215482.

10. Shon WJ (2016) Introducing the GentleWave System. Restor Dent Endod 41(3): 235.

11. Gu L, Kim J, Ling J, Choi K, Pashley D, et al. (2009) Review of Contemporary irrigant Agitation Techniques and Devices. J Endod 35(6): 791-804.

12. Dakin HD (1915) On the use of certain antiseptic substances in the treatment of infected wounds. Br Med J 2(2852): 318.

13. Estrela C, Estrela CRA, Barbin EL, Spano JCE, Marchesan MA, et al. (2002) Mechanism of action of sodium hypochlorite. Braz Dent J 13(2): 113.

14. Chiniforush N, Pourhajibagher M, Shahabi S, Bahador A (2015) Clinical Approach of High Technology Techniques for Control and Elimination of Endodontic Microbiota. J Laser Med Sci 6(4): 139-150.

15. Jurič IB, Anić I (2014) The Use of Lasers in Disinfection and Cleanliness of Root Canals: a Review. Acta Stomatol Croat 48(1): 6-15.

16. Byström A, Sundqvist G (1985) The antibacterial action of sodium hypochlorite and EDTA in 60 cases of endodontic therapy. Int Endod J 18(1): 35-40.

17. Hulsmann M, Heckendorff M, Lennon A (2003) Chelating agents in the root canal treatment: Mode of cation and indications for their use. Int Endod J 36(12): 810-831.

18. Plotino G, Grande NM, Mercade M, Cortese T, Staffoli S, et al. (2019) Efficacy of sonic and ultrasonic irrigation devices in the removal of debris from canal irregularities in artificial root canals. J Appl Oral Sci 27: e20180045.

19. Uroz Torres D, González Rodríguez MP, Ferrer Luque CM (2010) Effectiveness of the EndoActivator system in removing the smear layer after root canal instrumentation. J Endod 36(2): 308-311.

20. Townsend C, Maki J (2009) An In Vitro Comparison of New Irrigation and Agitation Techniques to Ultrasonic Agitation in Removing Bacteria From a Simulated Root Canal. J Endod 35(7): 1040-1043. 
21. Neilsen BA, Baumgartner JC (2007) Comparison of the EndoVac System to Needle Irrigation of Root Canals. J Endod 33(5): 611-615.

22. Guerisoli DM, Marchesan MA, Walmsley AD, Lumley PJ, Pecora JD (2002) Evaluation of smear layer removal by EDTAC and sodium hypochlorite with ultrasonic agitation. Int Endod J 35(5): 418-421.

23. Elmessiry A, Darrag MA, Ghoneim MW (2019) Effect of different irrigation solutions and techniques on pushout bond strength resin-based sealer. Tanta Dental Journal 16(1): 46-54.

24. Glassman DG, Charara K (2015) Apical Negative Pressure: Safety, Efficacy and Efficiency. Endodontic Irrigation pp: 157-171.

25. (2007) Rinsendo: A Unique Instrument for Root Canal Debridement. Inside Dentistry 3(5).

26. Ives $\mathrm{A}$, Chen $\mathrm{W}$, Jassemnejad $\mathrm{B}$, Bartels $\mathrm{K}$, Liu $\mathrm{H}$, et al. (2000) Laser-tissue photothermal interaction and tissue temperature change.

27. De Moor RJG, Blanken J, Meire M, Verdaasdonk R (2009) Laser induced explosive vapor and cavitation resulting in effective irrigation of the root canal. Part 2: Evaluation of the efficacy. Lasers Surg Med 41(7): 520-523.

28. Tennert C, Feldmann K, Haamann E, Al Ahmad A, Follo M, et al. (2014) Effect of photodynamic therapy (PDT) on Enterococcus Faecalis biofilm in experimental primary and secondary endodontic infections. BMC Oral Health 14(1): 132.

29. DiVito E, Peters OA, Olivi G (2012) Effectiveness of the erbium: YAG laser and new design radial and stripped tips in removing the smear layer after root canal instrumentation. Lasers Med Sci 27(2): 273-280.

30. Gupta J, Nikhil V, Jha P (2014) Correlation between machines assisted endodontic irrigant agitation and apical extrusion of debris and irrigant: a laboratory study. Scientific World Journal 2014: 346184.

31. Sigurdsson A, Garland RW, Le KT, Woo SM (2016) 12 -month healing rates after endodontic therapy using the novel GentleWave system: a prospective multicenter clinical study. J Endod 42(7): 1040-1048.

32. Sigurdsson A, Le KT, Woo SM, Rassoulian SA, McLachlan $\mathrm{K}$, et al. (2016) Six-month healing success rates after endodontic treatment using the novel GentleWave ${ }^{\mathrm{TM}}$ System: The pure prospective multicenter clinical study. Journal of clinical and Experimental Dentistry 8(3): 290298.
33. Vandrangi $P$ (2016) Evaluating the penetration depth of treatment fluids into dentinal tubules using the GentleWave system. Dentistry 6: 366.

34. Guo X, Miao H, Li L, Zhang S, Zhou D, et al. (2014) Efficacy of four different irrigation techniques combined with $60^{\circ} \mathrm{C} 3 \%$ sodium hypochlorite and $17 \%$ EDTA in smear layer removal. BMC Oral Health 14(1): 114.

35. Charara K, Friedman S, Sherman A, Kishen A, Malkhassian G, et al. (2016) Assessment of Apical Extrusion during Root Canal Irrigation with the Novel GentleWave System in a Simulated Apical Environment. J Endod 42(1): 135139.

36. Dai S, Xiao G, Dong N, Liu F, He S, et al. (2018) Bactericidal effect of a diode laser on Enterococcus Faecalis in human primary teeth-an in vitro study. BMC Oral Health 18(1): 154.

37. Inkson BJ (2016) Scanning Electron Microscope (SEM) and Transmission Electron Microscopy (TEM) of Materials Characterization. In book: Materials Characterization Using Non-destructive Evaluation (NDE) Methods pp: 17-43.

38. Demidova TN, Hamblin MR (2004) Photodynamic therapy targeted to pathogens. Int J Immunopathol Pharmacol 17(3): 245-254.

39. Foschi F, Fontana CR, Ruggiero K, Riahi R, Vera A, et al. (2007) Photodynamic inactivation of Enterococcus faecalis in dental root canals in vitro. Lasers Surg Med 39(10): 782-787.

40. Cheng X, Guan S, Lu H, Zhao C, Chen X, et al. (2012) Evaluation of the bactericidal effect of Nd:YAG, Er: YAG, Er,Cr:YSGG laser radiation, and antimicrobial photodynamic therapy (aPDT) in experimentally infected root canals. Lasers Surg Med 44(10): 824-831.

41. Abbott PV, Heijkoop PS, Cardaci SC, Hume WR, Heithersay GS (1991) An SEM study of the effects of different irrigation sequences and ultrasonics. Int Endod J 24(6): 308-316.

42. AlKahtani A, Alkahtany SM, Mahmood A, Elsafadi MA, Aldahmash AM, et al. (2014) Cytotoxicity of QMix ${ }^{\mathrm{TM}}$ endodontic irrigating solution on human bone marrow mesenchymal stem cells. BMC Oral Health 14(1): 27.

43. Inkson BJ (2016) In material characterization using nondestructive Evaluation (NDE) methods.

44. Eidler V, Linetskiy I, Hubálková $H$, Staňková $H$, Šmucler $\mathrm{R}$, et al. (2008) Ozone and Its Usage in General Medicine and Dentistry. A Review Article. Prague Med Rep 109(1): 
$5-13$.

45. Ferrer Luque CM, González Castillo S, Ruiz Linares M, Arias Moliz MT, Archilla AR, et al. (2015) Antimicrobial residual effects of irrigation regimens with maleic acid in infected root canals. J Biol Res 22(1): 1.

46. Forghani M, Afshari E, Parisay I, Garajian R (2017) Effect of a passive sonic irrigation system on the elimination of Enterococcus Faecalis from root canal systems of primary teeth, using different concentrations of sodium hypochlorite: An in vitro evaluation. J Dent Res Dent Clin Dent Prospects 11(3): 177-182.

47. Ghori S Gulabivata K, Premdas C, Spratt DA (2002) Evaluation of the antimicrobial efficacy of electrochemically activated water on selected isolates from the root canals. Int Endod J.

48. Hugo WB, Longworth AR (1964) Some aspects of the mode of action of chlorhexidine. J Pharm Pharmacol 16: 655-662.
49. Kakehashi S, Stanley HR, Fitzgerald RJ (1965) The effects of surgical exposures of dental pulps in germ free and conventional laboratory rats. Oral Surgery Oral Medicine Oral Pathology 20: 340-349.

50. Mohammadi Z, Jafarzadeh H, Shalavi S, Palazzi F (2017) Recent advances in root canal disinfection: A review. Iran Endod J 12(4): 402-406.

51. Wang QQ, Zhang CF, Yin XZ (2007) Evaluation of the Bactericidal Effect of Er,Cr:YSGG, and Nd:YAG Lasers in Experimentally Infected Root Canals. J of Endod 33(7): 830-832.

52. Schein B, Schilder H (2006) Endotoxin content in endodontically involved teeth. J Endod 1(1): 19-21.

53. Van der Sluis LW, Wu MK, Wesselink PR (2005) A comparison between a smooth wire and a K-file in removing artificially placed dentine debris from root canals in resin blocks during ultrasonic irrigation. Int Endod J 38(9): 593-596. 